\title{
Potential role of probiotics on colorectal cancer prevention
}

\author{
Mario Uccello', Giulia Malaguarnera ${ }^{2}$, Francesco Basile ${ }^{3}, V^{2}$ elia D'agata ${ }^{4}$, Michele Malaguarnera $^{2}$, Gaetano Bertino ${ }^{5}$, \\ Marco Vacante ${ }^{1}$, Filippo Drago ${ }^{2}$, Antonio Biondi ${ }^{3}$ \\ From XXV National Congress of the Italian Society of Geriatric Surgery \\ Padova, Italy. 10-11 May 2012
}

\begin{abstract}
Background: Colorectal cancer represents the most common malignancy of the gastrointestinal tract. Owing to differences in dietary habits and lifestyle, this neoplasm is more common in industrialized countries than in developing ones. Evidence from a wide range of sources supports the assumption that the link between diet and colorectal cancer may be due to an imbalance of the intestinal microflora.

Discussion: Probiotic bacteria are live microorganisms that, when administered in adequate amounts, confer a healthy benefit on the host, and they have been investigated for their protective anti-tumor effects. In vivo and molecular studies have displayed encouraging findings that support a role of probiotics in colorectal cancer prevention.

Summary: Several mechanisms could explain the preventive action of probiotics against colorectal cancer onset. They include: alteration of the intestinal microflora; inactivation of cancerogenic compounds; competition with putrefactive and pathogenic microbiota; improvement of the host's immune response; anti-proliferative effects via regulation of apoptosis and cell differentiation; fermentation of undigested food; inhibition of tyrosine kinase signaling pathways.
\end{abstract}

\section{Background}

Colorectal cancer $[\mathrm{CRC}]$ is one of the major health problems in the world, representing the most common malignancy of the gastrointestinal [GI] tract. CRC is more frequent in industrialized countries than in developing ones with a four times higher incidence [1]. Differences in dietary habits and lifestyle rather than racial factors may explain this gap as it has been demonstrated by studies on migrants. The diet is likely to play a key role in the pathogenesis of CRC. Epidemiological studies have shown that the consumption of red meat and animal fat is associated with an increased risk for CRC development [2], whereas a diet rich in fruits and vegetables appears to be protective against CRC [3]. Evidence from a wide range of sources supports the assumption that the link between diet and

\footnotetext{
* Correspondence: m.malaguarnera@email.it

${ }^{2}$ International PhD programme in Neuropharmacology, University of Catania, Italy

Full list of author information is available at the end of the article
}

CRC may be due to an imbalance of the intestinal microflora [4]. At birth, the GI tract is colonized by microbes and remains the home for several populations of microorganisms throughout the life of the host. The 'normal' gut microflora consists of bacterial species with morphological, physiological and genetic features that let it to colonize and multiply under particular conditions at certain sites, coexist with other colonizing microorganisms and competitively inhibit the growth of pathogenic bacteria. Nevertheless, some environmental factors such as diet and drugs can alter the composition of the resident microbiota, with consequent dysmicrobia and negative implications for the health of the individual. The colonic microflora is very rich and dominated by strict anaerobic bacteria such as Bacteroides spp., Fusobacterium spp., Clostridium spp, and many others [5]. Probiotic bacteria may be defined as live microorganisms which when administered in adequate amounts confer a health benefit on the host' [6], and they most frequently belong to the lactic acid bacteria [LAB] 
category, such as Lactobacillus spp. and Bifidobacterium spp. LAB are widely available, for instance, in yogurts and other functional foods such as cheese, fermented and unfermented milks, juices, smoothies, cereal, nutrition bars and infant/toddler formula [7]. A number of studies in animal models and in human population have demonstrated that the consumption of probiotics is effective in various medical conditions such as lactose intolerance, antibiotic-induced diarrhea, gastroenteritis, constipation, and genitourinary tract infections [8]. Moreover, accumulating evidence suggests that the ingestion of probiotics may be able to play a preventive role in the onset of CRC [4]. This observation seems to be very interesting as it would make possible an effective strategy for CRC primary prevention. This review is merely intended at providing an outline of the possible mechanisms whereby probiotics may exert their beneficial effects for CRC prevention. We have given greater emphasis on those novel mechanisms, such as the inhibition of tyrosine kinase signaling pathways and anti-proliferative effects, that have not been thoroughly discussed yet.

\section{Discussion}

\section{Mechanisms of CRC prevention exerted by probiotics}

Despite the great number of studies in the literature, the precise mechanisms by which probiotics may prevent CRC still remain not perfectly clear. However, it is conceivable that they include: alteration of the intestinal microflora; inactivation of cancerogenic compounds; competition with putrefactive and pathogenic microbiota; improvement of the host's immune response; anti-proliferative effects via regulation of apoptosis and cell differentiation; fermentation of undigested food; inhibition of tyrosine kinase signaling pathways. The coadministration of probiotics with prebiotics [which are defined as 'selectively fermented ingredients that allow specific changes, both in the composition and/or activity in the gastrointestinal microflora that confer benefits upon host wellbeing and health' [9], the so-called synbiotics, can increase the effectiveness of these anti-cancer mechanisms $[10,11]$. Moreover, the acidification of $\mathrm{pH}$, although not considered as a distinct mechanism of action, is an intrinsic and fundamental feature whereby many probiotics carry out their metabolic activities [12,13]. These potential mechanisms will be discussed individually now.

\section{Alteration of the intestinal microflora metabolism}

Glucuronide conjugation is one of the major metabolic processes occurring in the liver. It is critical to metabolize hormones, and also to inactivate toxic and carcinogenic compounds of endogenous and exogenous origin. The conjugation with glucuronic acid results in polar metabolites that are efficiently eliminated in the bile [14]. The deconjugation of these glucuronides in the intestine by bacterial $\beta$-glucuronidase leads to the release of aglycones that are potentially carcinogenic substances [15]. There are other fecal bacterial enzymes, including azoreductase and nitroreductase, which catalyze the liberation of procarcinogenic substances in the intestine $[16,17]$. The alteration of the intestinal metabolism by modulating the activity of these bacterial enzymes may be one of the possible mechanisms by which probiotics may reduce the risk for the onset of CRC [18]. It has been demonstrated that a yogurt feeding can reduce the levels of $\beta$-glucuronidase and nitroreductase contained in the large intestine of mice bearing colon cancer [19]. Goldin and Gordbach [18] reported a decrease in fecal bacterial enzyme activity after a Lactobacillus acidophilus feeding in animal models. The same authors [20] recruited 21 young healthy subjects for a study aimed at investigating the effect of $L$. acidophilus oral supplements on the enzyme activity of $\beta$-glucuronidase, nitroreductase and azoreductase. Both two strains of L. acidophilus used in the study [N-2 and NCFM] caused a significant decrease in the activities of the three fecal enzymes after a ten-days lactobacilli feeding. Having stopped the bacterial feedings, fecal enzyme levels returned to normal after four weeks, suggesting that continuous ingestion of these organisms is required for these enzyme effects to be maintained in the microflora. However, apparently ambiguous or discordant results have been shown by most human studies designed to investigate the effects of probiotics supplementation on fecal enzyme bacterial activity [21-26]. For example, Marteau et $a l$. [24] reported a decrease only in nitroreductase activity after a three weeks-period of ingesting a fermented dairy product containing L. acidophilus, Bifidobacterium bifidum, and mesophilic cultures [Streptococcus lactis and Streptococcus cremoris] while $\beta$-glucuronidase and azoreductase activities did not change. Indeed, these findings suggest that the capability of modulating fecal enzymes bacteria activity is a strain-specific characteristic for probiotics. The duration and amount of probiotic intake are other considerable factors. Moreover, the degree of relationship between the ability of probiotics to influence the bacterial metabolism and the prevention of CRC has to be better clarified.

\section{Inactivation of cancerogenic compounds}

A meta-analysis of 15 prospective studies showed a relative risk of developing CRC of 1.28 for subjects with a higher consumption of red meat, when compared with people who eat red meat in lower quantities [2]. Several hypotheses have been proposed to explain this relationship. Heterocyclic aromatic amines [HCA], formed as a result of cooking meat at high temperatures, are among the substances called into question $[27,28]$. Intestinal 
microbiota can activate HCA to their active derivatives such as the mutagenic pyrolyzates 3-amino-1,4-dimethyl5H-pyrido-[4,3-b]indole [Trp-P-1], 3-amino-1-methyl-5Hpyrido-[4,3-b]indole [Trp-P-2], 2-amino-3-methylimidazo [4,5-f]quinoline [IQ], 2-amino-1-methyl-6-phenylimidazo [4,5-b]pyridine [PhIP], 2-amino-3,4-dimethylimidazo[4,5-f] quinoline [MeIQ], and 2-amino-3,8-dimethylimidazo[4,5f]quinoxaline [MeIQx] $[29,30]$. Such powerful mutagenic substances may act with the colonic mucosa, causing tumorigenic mutations [30]. LAB and other commensal bacteria have been found to bind or metabolize several carcinogens, including HCA and $\mathrm{N}$-nitroso compounds. Binding and/or degradation well correlates with the reduction in mutagenicity observed after exposure of HCA to the bacterial strains [31-33]. According to the literature, the binding or degradation of HCA by probiotics could be one of the main mechanisms of removing carcinogens out of the human body. Orrhage et al. [32] studied the in vitro capacity of some LAB to bind mutagenic HCA formed during the cooking of protein-rich food. The binding of the mutagens Trp-P-2, PhIP, IQ and MeIQx by the bacterial strains was analyzed by HPLC. Trp-P-2 was almost completely and irreversibly bound while the binding of PhIP, a major mutagen in the western diet, reached about $50 \%$. IQ and MeIQx were slightly less well bound. Sreekumar and Hosono [34,35] demonstrated that different strains of Lactobacillus gasseri and Bifidobacterium longum strongly bound Trp-P-1 and Trp-P-2. Oral supplementation with L. acidophilus NCFB1748 and B. longum BB536 decreased the bioavailability of Trp-P-2 in the GI tract and other several tissues in mice [36]. Cell fractions of L. acidophilus and Bifidobacterium spp. have been found to bind Trp-P-1 and decrease its genotoxicity [37]. Most data suggest that the binding of mutagens could be due to the bacterial cell wall $[32,37,38]$ though the antimutagenic effect of Lactobacillus plantarum KLAB21 is mediated by three extracellular glycoproteins [39]. Challa et al. [40] demonstrated that a B. longum and lactulose feeding in rats significantly increased the activity of colonic glutathione S-transferase, which is one of the Phase II enzymes involved in the detoxification of toxic metabolites and carcinogens, and suppressed azoxymethane [AOM]induced colonic aberrant crypt foci [ACF] that are preneoplastic markers. More recently, Lactobacillus casei DN 114001 has been shown to grow and survive in the presence of IQ, MelQx and PhIP and to decrease their concentrations [12].The probiotic ability to bind or metabolize toxic compounds depends on $\mathrm{pH}$ and other physicochemical conditions [12,32,33]. All these results indicate that the detoxification of cooked food mutagenic compounds, commonly found in the western meat-rich diet, may be one of the main mechanisms by which LAB antagonize the onset of CRC.

\section{Competition with putrefactive and pathogenic microbiota}

The GI tract, particularly the colon, is very heavily populated with bacteria. Although most gut bacteria are benign, some species are pathogenic and may be involved in the onset of acute and chronic disorders, including CRC [41]. It is established that a diet rich in animal fat stimulates the growth of secondary bile salt-producing bacteria and further studies have shown that secondary bile salts are cytotoxic and carcinogenic [42,43]. A diet rich in red meat also facilitates the growth of sulfatereducing bacteria producing hydrogen sulfide which experimentally is known to be genotoxic [44-46]. Putrefactive intestinal microbiota such as Bacteroides spp. and Clostridium spp. have been implicated in the pathogenesis of CRC [47] while numerous LAB have been shown to possess cancer-preventing attributes [31]. Rafter et al. [48] found that the synbiotic combination of a specific oligofructose-enriched inulin with probiotics on the fecal flora of polyp and colon cancer patients caused an increase in the number of some groups of LAB [Bifidobacterium in both groups and Lactobacillus in polyp patients], whereas the number of Clostridium perfringens in polyp patients significantly decreased. The consumption of probiotics alone have also proved effectiveness to cause changes in GI microflora, with a significant reduction of fecal putrefactive bacteria, such as coliforms, and an increase of LAB $[49,50]$. These effects may be mediated by adherence to enterocytes and the $\mathrm{pH}$ lowering [13,51]. Furthermore, O'Mahony et al. reported that the enteric flora modification in interleukin-10 [IL-10] knockout mice by probiotic Lactobacillus salivarius UCC118 resulted in a reduced prevalence of colon cancer [49]. Thus, probiotics may counteract CRC development also through a mechanism of competition with pathogenic intestinal microbiota.

\section{Improvement of the host's immune response}

The immune system plays an important role in the control of tumor promotion and progression. The close interaction of several elements of the immune system, such as antigen-presenting cells [APCs], and different subsets of $\mathrm{T}$ cells, B cells and natural killer [NK] cells, is critical for the generation of an effective anti-tumour immune response [52]. Besides other potential effects in the prevention of cancer, probiotics have been suggested to enhance the mucosal and system immune response [53]. In 1981, Yokokura [54] screened 26 strains of 14 different species of LAB for in vivo anti-tumor activities against a transplantable mouse sarcoma, and noticed that some of these strains had potent anti-tumor effects. Among them, especially Lactobacillus casei Shirota [LcS] showed a high potential. Since such strain is not directly cytotoxic to tumor cells in vitro, it has been postulated 
that its anti-tumor effects may be mediated by the enhancement of the host's immune system [55]. This hypothesis has elicited further investigations on the antitumor and immunoregulatory action of LCS in various experimental models [56-58]. Oral administration of LcS has exhibited beneficial effects in both humans and animals as well as anti-tumor activity against human bladder cancer cells in clinical trials $[59,60]$. LcS has been shown to possess powerful anti-tumor and anti-metastatic effects on transplantable tumor cells and to suppress chemically-induced carcinogenesis in rodents. In particular, It has been noted that the intrapleural administration of LcS into tumor-bearing mice has induced the production of several cytokines, such as Interferon- $\gamma$ [IFN- $\gamma]$, interleukin- $\beta$ [IL-1 $\beta]$ and tumor necrosis factor- $\alpha$ [TNF- $\alpha$ ], leading to the inhibition of tumor growth and to an increased survival $[58,61]$. After LcS is ingested by the host, it is incorporated into M cells in Peyer's patches and digested to form active components. In Peyer's patches, macrophages or dendritic cells [DCs], after phagocytosing LcS, become able to produce several cytokines, especially TNF- $\alpha$. Then, the components of LcS digested in Peyer's patches are recognized through tolllike receptor 2 in APCs, and lead to the production of several cytokines that stimulate different responses in host immune cells [62]. Lcs has also exhibited a strong anti-tumor effect in mice by regulating the host immune response in a 3-methylcholanthrene [MC]-induced carcinogenesis model [63] that has been used to induce many tumors, including colon cancer model $[64,65]$. An LcS oral feeding of mice is likely to counteract MC-induced tumorigenesis by ameliorating the host immune responses which have been disrupted during $\mathrm{MC}$ carcinogenesis. A possible mechanism of carcinogenesis prevention is the proliferation and activation of NK cells [66]. NK cells are large granular lymphocytes derived from bone marrow, and have a critical role in immune surveillance against tumor development [67]. Other possible effector cells that may respond to LcS and other probiotics are DCs $[62,68]$ : they represent important types of cells involved in the presentation of several antigens and in the production of cytokines [69]. In addition, oral administration of LcS has been shown to stimulate type 1 helper $\mathrm{T}$ cells, activate the cellular immune system, and inhibit the incidence of tumors and IgE production in mice [70]. More recently, it has been reported that LcS has suppressed murine tumorigenesis with potent elicitation to produce interleukin-12 [IL-12] by bone marrow-derived cells in vitro [71] and to inhibit of interleukin-6 [IL-6] production in the colonic mucosa [72]. In numerous studies, other probiotic strains have shown remarkable immunoprotective properties through the increase of specific and non-specific mechanisms that have anti-tumor effects. For instance, Lee et al. [73] reported that the administration for four weeks of L. acidophilus SNUL, L. casei YIT9029 and B. longum HY8001, for instance, increased the survival rate of mice injected with tumor cells. The increase of survival was correlated with an increase in cellular immunity as reflected by an augmentation in the number of total $\mathrm{T}$ cells, NK cells and $\mathrm{MHC}$ class $\mathrm{II}^{+}$cells, and $\mathrm{CD} 4^{-} \mathrm{CD} 8^{+}$ $\mathrm{T}$ cells in flow cytometry analysis. These findings suggest that the treatment with probiotics has the potential to prevent CRC by modulation of the host's immune system, specifically cellular immune responses.

\section{Anti-proliferative effects via regulation of apoptosis and cell differentiation}

Apoptosis is a genetically determined mode of cell death playing a key role in the regulation of cell numbers. In many types of cancer, a reduced ability to trigger apoptosis is an important pathogenetic event that is accompanied by alteration of control processes of cell proliferation [74]. The regulation of cell survival and death with molecules acting on the apoptotic process can have a huge chemopreventive and therapeutic potential [75]. There is much evidence that probiotics can have a role in the regulation of cell proliferation and apoptosis which are potentially crucial mechanisms in the prevention of CRC. Iyer et al. [76] found that Lactobacillus reuteri suppressed TNFinduced NF- $\kappa \mathrm{B}$ activation in a dose and time-dependent manner. L. reuteri may regulate cell proliferation by promoting apoptosis of activated immune cells via inhibition of IkBa ubiquitination and enhancing pro-apoptotic mitogen activated protein kinase [MAPK] signaling. The probiotic mixture VSL\#3 has been reported to suppress the COX-2 expression in Colo320 and SW480 intestinal epithelial cells [77]. The expression of COX-2 is increased in colorectal tumors [78], and this elevation can protect intestinal epithelial cells from apoptosis $[79,80]$. Recently, rodent studies have demonstrated that the synbiotic combination of resistant starch and Bifidobacterium lactis has exerted a pro-apoptotic action in response to the carcinogen, AOM $[10,81]$. Other studies have postulated that probiotics possess CRC-protective effects by altering the differentiation process of tumor cells. Using a cultured human colon cancer cell line [HT-29], Baricault et al. [82] studied the effect of fermented milks on colon cancer cell proliferation and growth. Milks were fermented by one of the following bacterial populations: Lactobacillus helveticus, Bifidobacterium, L. acidophilus or a mix of Streptococcus thermophilus and Lactobacillus bulgaricus. After HT-29 cells were added to the fermented milk, only L. acidophilus was found to have no effects on both cell growth and differentiation while the three other bacterial strains induced a significant, although variable, reduction in the growth rate of HT-29 cells, which resulted in a $10-50 \%$ decrease in the cell number at steady-state. 
Concomitantly, the specific activities of dipeptidyl peptidase IV, which is a sensitive and specific marker of HT-29 cell differentiation, and those of three other brush border enzymes [sucrase, aminopeptidase $\mathrm{N}$ and alkaline phosphatase] were significantly increased, thus suggesting that these cells may have entered a differentiation process. Moreover, the combination of Bifidobacterium breve $\mathrm{R} 0070$ + Lactobacillus lactis R1058 + oligoalternan inhibited the proliferation of HT-29 cells in absence of cytotoxic effect [83]. This could be explained by the induction from an undifferentiated phenotype to a more differentiated one. In fact, the results showed that cancerous HT-29 cells treated with the synbiotic, when compared with the differentiated ones, reached the same rate expression of intestinal alkaline phosphatase, a biomarker of colic differentiation [84]. Singh et al. [85] demonstrated that a dietary administration in rats of lyophilized cultures of B. longum resulted in a significant suppression of colon tumor incidence and tumor multiplicity, and it also reduced the tumor volume. Analyses on intermediate biomarkers also revealed that the ingestion of $B$. longum inhibited AOMinduced cell proliferation through a reduction in ornithine decarboxylase [ODC] activity. ODC is involved in the biosynthesis of polyamines that cause cell proliferation and differentiation of the colonic mucosa [86]. According to these data, an improved understanding of LAB-mediated effects on apoptosis and differentiation signalling pathways may facilitate the development of future probiotics-based regimens for the prevention of CRC.

\section{Fermentation of undigested food}

The bacterial transformation of dietary components in the intestinal lumen may be associated with the production of cancer-preventive agents and may therefore be another mechanism whereby probiotics can influence CRC risk. The bacterial fermentation of indigestible carbohydrates generates short-chain fatty acids [SCFA] and gas; while the gas is eliminated in the feces, SCFA [mainly acetate, propionate and butyrate] represent nutrients and growth signals for the intestinal mucosa and may play a role in CRC prevention [87]. They reduce, for instance, the concentration of secondary bile salts. Butyrate, that is the most widely studied of these SCFA, is a preferred energy source for colonocytes and is likely to promote a normal phenotype in these cells. In CRC cell lines, butyrate enhances cellular differentiation and reduces proliferation $[88,89]$. In human studies, butyrate and the associated lowering of luminal $\mathrm{pH}$ are correlated with a reduced risk of CRC [90,91]. A specific strain [MDT-1] of the ruminal bacterium Butyrivibrio fibrisolvens has been evaluated for use as a probiotic to prevent CRC cancer since it produces high amounts of butyrate [92]. Using a mouse model of colon cancer, the administration of MDT-1 has reduced the number of ACF and the percentage of mice with an increased proportion of ACF. Furthermore, the human probiotic Propionibacterium spp. has been shown to kill CRC cells through apoptosis in vitro via its metabolites, the SCFA, acetate and propionate $[93,94]$. However, synbiotics would be more active than probiotics alone in increasing the production of SCFA and consequently protect against CRC onset $[10,95]$. A possible explanation is that the interaction of the immunomodulating properties of probiotic bacteria and butyrate, which is more produced via fermentation of prebiotics, results in an upregulation of apoptosis $[10,11]$. In addition to SCFA, probiotics are involved in the production of another group of fatty acids, termed conjugated linoleic acids [CLAs]. These are a group of isomers of linoleic acid that have been shown to exert numerous health benefits, including anti-inflammatory and anti-carcinogenic effects $[96,97]$. In rodent studies CLA has been shown to reduce the incidence of colonic tumors $[98,99]$. Using animal models, Ewaschuk et al. [100] demonstrated that the probiotic strains in the mixture VSL\#3 are able to convert linoleic acid into CLA, inducing the upregulation of PPAR $\gamma$, a reduction in colonic tumor cells viability, and the induction of apoptosis. These studies support a role for supplemental probiotics as a strategy for preventing CRC by fermentation of indigestible food, but further investigations are needed.

\section{Inhibition of tyrosine kinase signaling pathways}

Signaling pathways are represented by a series of biochemical events whereby a cell communicates with the extracellular environment. Signaling pathways are activated by receptors or cytoplasmic proteins with tyrosine kinase activity and play a critical role in carcinogenesis [101]. Saccharomyces boulardii [Sb] is a safety probiotic agent used to prevent or treat a wide variety of human GI disorders [102,103]. It has been reported that $\mathrm{Sb}$ acts through modulation of the host signaling pathways that regulate the intestinal mucosal inflammatory response. In particular, Sb down-regulates MAPK signaling pathways $[104,105]$ that are located downstream of many growthfactor receptors, including the epidermal growth factor receptor [EGFR]. The EGF receptor family consists of four members: ErbB1/EGFR/HER1, ErbB2/HER2/Neu, ErbB3/ HER-3 and ErbB4/HER-4 that are important for cancer development [106]. Chen et al. [107] wanted to examine the effects of $\mathrm{Sb}$ on tumor development in $A p c^{\mathrm{Min}}$ mice, an animal model used for quantitative and mechanistic studies of the induction of intestinal tumors [108]. Sb prevented cancer cell colony formation, reduced EGFmediated cell proliferation, and increased apoptosis. Both in vitro and in vivo effects were consistent with inhibition of the EGFR and Akt pathways. Furthermore, a laboratory study by Ma et al. [109] demonstrated that the probiotic Bacillus polyfermenticus suppressed colon cancer cells growth in vitro and colon cancer tumor growth in vivo. 
Bacillus polyfermenticus exerted its anticancer effect through the reduction of ErbB2 and ErbB3 and their downstream signaling molecules E2F-1 and cyclin D1. Thus, in addition to the other anti-tumorigenic effects, probiotics may inhibit EGFR and other tyrosine kinase signaling pathways and thereby may also serve a novel therapeutic or prophylactic role in intestinal malignancies.

\section{Conclusions}

Although a wide range of studies have brought to growing remarkable findings in recent years, it has not still been possible to obtain conclusive clinical evidence supporting the role of probiotics in CRC prophylaxis. Since CRC is an impractical endpoint in terms of numbers of subjects, cost, study duration and ethical considerations, probiotic intervention studies often use recurrence of preneoplastic lesions or intermediate biomarkers of cancer as an endpoint $[110,111]$. Several mechanisms could explain the preventive action of probiotics against CRC onset. All of the CRC-preventing mechanisms previously discussed are supported in varying degrees from in vitro and animal model studies, some of them even from human clinical studies. We are not still able to determine which mechanisms are most effective. Most likely distinct strains of probiotics operate with specific mechanisms. Further investigations are strongly required in order to establish the impact of each mechanism and the real usefulness of probiotics in CRC prevention.

\section{Acknowledgements}

MM was supported by the International PhD programme in

Neuropharmacology, University of Catania. The authors wish to thank Alessia Trovato for carefully editing the manuscript and contributing to language revision.

This article has been published as part of BMC Surgery Volume 12 Supplement 1, 2012: Selected articles from the XXV National Congress of the Italian Society of Geriatric Surgery. The full contents of the supplement are available online at http://www.biomedcentral.com/bmcsurg/supplements/12/S1.

\section{Author details \\ 'Department of Senescence, Urological and Neurological Sciences, Cannizzaro Hospital Via Messina 829, 95125, University of Catania, Italy. ${ }^{2}$ International PhD programme in Neuropharmacology, University of Catania, Italy. ${ }^{3}$ Department of General Surgery, Section of General Surgery and Oncology, Vittorio Emanuele Hospital, Via Plebiscito 628 University of Catania, 95123 Catania, Italy. ${ }^{4}$ Department of Biomedical Sciences, Via S. Sofia, 87, 95123, University of Catania, Italy. University of Catania, Italy. ${ }^{5}$ Department of Medical and Pediatric Sciences Via S. Sofia, 87, 95123, University of Catania, Italy.}

\section{Authors' contributions}

MU: conception and design, drafting the manuscript, given final approval of the version to be published; GM, VDA, MM, MV: drafting the manuscript, given final approval of the version to be published; FB, GB, FD, AB: critical revision, given final approval of the version to be published.

\section{Competing interests}

The authors declare that they have no competing interests.

\section{References}

1. Haggar FA, Boushey RP: Colorectal cancer epidemiology: incidence, mortality, survival, and risk factors. Clin Colon Rectal Surg 2009, 22:191-197.

2. Larsson SC, Wolk A: Meat consumption and risk of colorectal cancer: a meta-analysis of prospective studies. Int J Cancer 2006, 119:2657-2664.

3. Riboli E, Norat T: Epidemiologic evidence of the protective effect of fruit and vegetables on cancer risk. Am J Clin Nutr 2003, 78:559S-569S.

4. Rafter J: The effects of probiotics on colon cancer development. Nutr Res Rev 2004, 17:277-284.

5. Rastall RA: Bacteria in the gut: friends and foes and how to alter the balance. J Nutr 2004, 134:2022S-2026S.

6. FAO, WHO: Evaluation of health and nutritional properties of probiotics in food, including powder milk with live lactic acid bacteria. Food and Agricultural Organization of United Nations and World Health Organization Expert Consultation Report 2001 [http://www.who.int/foodsafety/ publications/fs_management/en/probiotics.pdf].

7. Davis CD, Milner JA: Gastrointestinal microflora, food components and colon cancer prevention. J Nutr Biochem 2009, 20:743-752.

8. Iannitti T, Palmieri B: Therapeutical use of probiotic formulations in clinical practice. Clin Nutr 2010, 29:701-725.

9. Roberfroid M: Prebiotics: the concept revisited. J Nutr 2007, 137:830S-837S

10. Le Leu RK, Hu Y, Brown IL, Woodman RJ, Young GP: Synbiotic intervention of Bifidobacterium lactis and resistant starch protects against colorectal cancer development in rats. Carcinogenesis 2010, 31:246-251.

11. Perdigón G, Fuller R, Raya R: Lactic acid bacteria and their effect on the immune system. Curr Issues Intest Microbiol 2001, 2:27-42.

12. Nowak A, Libudzisz Z: Ability of probiotic Lactobacillus casei DN 114001 to bind or/and metabolise heterocyclic aromatic amines in vitro. Eur J Nutr 2009, 48:419-427.

13. Rowland IR, Rumney CJ, Coutts JT, Lievense LC: Effect of Bifidobacterium longum and inulin on gut bacterial metabolism and carcinogen-induced aberrant crypt foci in rats. Carcinogenesis 1998, 19:281-285.

14. Tephly TR, Burchell B: UDP-glucuronosyltransferases: a family of detoxifying enzymes. Trends Pharmacol Sci 1990, 11:276-279.

15. Reddy BS, Mangat S, Weisburger JH, Wynder EL: Effect of high-risk diets for colon carcinogenesis on intestinal mucosal and bacterial betaglucuronidase activity in F344 rats. Cancer Res 1977, 37:3533-3536.

16. Hill MJ: The role of colon anaerobes in the metabolism of bile acids and steroids, and its relation to colon cancer. Cancer 1975, 36:2387-2400.

17. Goldin BR, Gorbach SL: The relationship between diet and rat fecal bacterial enzymes implicated in colon cancer. J Natl Cancer Inst 1976, 57:371-375.

18. Goldin BR, Gorbach SL: Alterations of the intestinal microflora by diet, oral antibiotics, and Lactobacillus: decreased production of free amines from aromatic nitro compounds, azo dyes, and glucuronides. J Natl Cancer Inst 1984, 73:689-695.

19. de Moreno de LeBlanc A, Perdigón G: Reduction of beta-glucuronidase and nitroreductase activity by yoghurt in a murine colon cancer model. Biocell 2005, 29:15-24.

20. Goldin BR, Gorbach SL: The effect of milk and lactobacillus feeding on human intestinal bacterial enzyme activity. Am J Clin Nutr 1984, 39:756-761.

21. Goldin BR, Swenson L, Dwyer J, Sexton M, Gorbach SL: Effect of diet and Lactobacillus acidophilus supplements on human fecal bacterial enzymes. J Natl Cancer Inst 1980, 64:255-261.

22. Lidbeck A, Nord CE, Gustafsson JA, Rafter J: Lactobacilli, anticarcinogenic activities and human intestinal microflora. Eur J Cancer Prev 1992, 1:341-353.

23. Tannock GW, Munro K, Harmsen HJ, Welling GW, Smart J, Gopal PK: Analysis of the fecal microflora of human subjects consuming a probiotic product containing Lactobacillus rhamnosus DR20. App/ Environ Microbiol 2000, 66:2578-2588.

24. Marteau $P$, Pochart $P$, Flourié $B$, Pellier $P$, Santos $L$, Desjeux JF, Rambaud JC: Effect of chronic ingestion of a fermented dairy product containing Lactobacillus acidophilus and Bifidobacterium bifidum on metabolic activities of the colonic flora in humans. Am J Clin Nutr 1990, 52:685-688.

25. Piccinni G, Testini M, Angrisano A, Lissidini G, Gurrado A, Memeo R, Basile F, Biondi A: Nutritional support in patients with acute pancreatitis. Front Biosci (Elite Ed) 2012, 4:1999-2006.

26. Bertkova I, Hijova E, Chmelarova A, Mojzisova G, Petrasova D, Strojny L, Bomba A, Zitnan R: The effect of probiotic microorganisms and bioactive 
compounds on chemically induced carcinogenesis in rats. Neoplasma 2010, 57:422-428.

27. Felton JS, Knize MG, Wu RW, Colvin ME, Hatch FT, Malfatti MA: Mutagenic potency of food-derived heterocyclic amines. Mutat Res 2007, 616:90-94

28. Turesky RJ: Formation and biochemistry of carcinogenic heterocyclic aromatic amines in cooked meats. Toxicol Lett 2007, 168:219-227.

29. Van Tassell RL, Kingston DG, Wilkins TD: Metabolism of dietary genotoxins by the human colonic microflora; the fecapentaenes and heterocyclic amines. Mutat Res 1990, 238:209-221.

30. Wakabayashi K, Nagao M, Esumi H, Sugimura T: Food-derived mutagens and carcinogens. Cancer Res 1992, 52:2092s-2098s.

31. Kumar M, Kumar A, Nagpal R, Mohania D, Behare P, Verma V, Kumar P, Poddar D, Aggarwal PK, Henry CJ, Jain S, Yadav H: Cancer-preventing attributes of probiotics: an update. Int J Food Sci Nutr 2010, 61:473-496.

32. Orrhage K, Sillerström E, Gustafsson JA, Nord CE, Rafter J: Binding of mutagenic heterocyclic amines by intestinal and lactic acid bacteria. Mutat Res 1994, 311:239-248.

33. Ragusa M, Statello L, Maugeri M, Majorana A, Barbagallo D, Salito L, Sammito M, Santonocito M, Angelica R, Cavallaro A, Scalia M, Caltabiano R, Privitera G, Biondi A, Di Vita M, Cappellani A, Vasquez E, Lanzafame S, Tendi E, Celeste S, Di Pietro C, Basile F, Purrello M: Specific alterations of the microRNA transcriptome and global network structure in colorectal cancer after treatment with MAPK/ERK inhibitors. J Mol Med (Berl)

34. Sreekumar $\mathrm{O}$, Hosono A: The antimutagenic properties of a polysaccharide produced by Bifidobacterium longum and its cultured milk against some heterocyclic amines. Can J Microbiol 1998, 44:1029-1036.

35. Sreekumar $\mathrm{O}$, Hosono A: The heterocyclic amine binding receptors of Lactobacillus gasseri cells. Mutat Res 1998, 421:65-72.

36. Orrhage KM, Annas A, Nord CE, Brittebo EB, Rafter JJ: Effects of lactic acid bacteria on the uptake and distribution of the food mutagen Trp-P-2 in mice. Scand J Gastroenterol 2002, 37:215-221.

37. Zhang $X B$, Ohta $Y$ : Antimutagenicity of cell fractions of microorganisms on potent mutagenic pyrolysates. Mutat Res 1993, 298:247-253.

38. Sreekumar O, Hosono A: Antimutagenicity and the influence of physical factors in binding Lactobacillus gasseri and Bifidobacterium longum cells to amino acid pyrolysates. J Dairy Sci 1998, 81:1508-1516.

39. Rhee $\mathrm{CH}$, Park HD: Three glycoproteins with antimutagenic activity identified in Lactobacillus plantarum KLAB21. App/ Environ Microbio/ 2001, 67:3445-3449.

40. Challa A, Rao DR, Chawan CB, Shackelford L: Bifidobacterium longum and lactulose suppress azoxymethane-induced colonic aberrant crypt foci in rats. Carcinogenesis 1997, 18:517-521.

41. Manning TS, Gibson GR: Microbial-gut interactions in health and disease. Prebiotics. Best Pract Res Clin Gastroenterol 2004, 18:287-298.

42. Nagengast FM, Grubben MJ, van Munster IP: Role of bile acids in colorectal carcinogenesis. Eur J Cancer 1995, 31A:1067-1070.

43. Merchant BN, Rogers CM, Trivedi B, Morrow J, Coffey RJ: Ligand-dependent activation of the epidermal growth factor receptor by secondary bile acids in polarizing colon cancer cells. Surgery 2005, 138:415-421.

44. Kanazawa K, Konishi F, Mitsuoka T, Terada A, Itoh K, Narushima S, Kumemura M, Kimura $\mathrm{H}$ : Factors influencing the development of sigmoid colon cancer. Bacteriologic and biochemical studies. Cancer 1996, 77:1701-1706.

45. Huycke MM, Gaskins HR: Commensal bacteria, redox stress, and colorectal cancer: mechanisms and models. Exp Biol Med (Maywood) 2004, 229:586-597.

46. Attene-Ramos MS, Wagner ED, Gaskins HR, Plewa MJ: Hydrogen sulfide induces direct radical-associated DNA damage. Mol Cancer Res 2007 5:455-459.

47. Sobhani I, Tap J, Roudot-Thoraval F, Roperch JP, Letulle S, Langella P, Corthier G, Tran Van Nhieu J, Furet JP: Microbial dysbiosis in colorectal cancer (CRC) patients. PLoS One 2011, 6:e16393.

48. Rafter J, Bennett M, Caderni G, Clune Y, Hughes R, Karlsson PC, Klinder A, O'Riordan M, O'Sullivan GC, Pool-Zobel B, Rechkemmer G, Roller M, Rowland I, Salvadori M, Thijs H, Van Loo J, Watzl B, Collins JK: Dietary synbiotics reduce cancer risk factors in polypectomized and colon cancer patients. Am J Clin Nutr 2007, 85:488-496.

49. O'Mahony L, Feeney M, O'Halloran S, Murphy L, Kiely B, Fitzgibbon J, Lee G, O'Sullivan G, Shanahan F, Collins JK: Probiotic impact on microbial flora, inflammation and tumour development in IL-10 knockout mice. Aliment Pharmacol Ther 2001, 15:1219-1225.

50. Berretta M, Lleshi A, Fisichella R, Berretta S, Basile F, Li Volti G, Bolognese A, Biondi A, De Paoli P, Tirelli U, Cappellani A: The role of nutrition in the development of esophageal cancer: what do we know? Front Biosci (Elite Ed) 2012, 4:351-7.

51. Trejo FM, Minnaard J, Perez PF, De Antoni GL: Inhibition of Clostridium difficile growth and adhesion to enterocytes by Bifidobacterium supernatants. Anaerobe 2006, 12:186-193.

52. Gabrilovich D, Pisarev V: Tumor escape from immune response: mechanisms and targets of activity. Curr Drug Targets 2003, 4:525-536.

53. Sekine K, Toida T, Saito M, Kuboyama M, Kawashima T, Hashimoto Y: A new morphologically characterized cell wall preparation [whole peptidoglycan] from Bifidobacterium infantis with a higher efficacy on the regression of an established tumor in mice. Cancer Res 1985, 45:1300-1307.

54. Yokokura T, Kato I, Mutai M: Antitumor effect of Lactobacillus casei (LC 9018). In Intestinal flora and carcinogenesis. Gakkai-Syuppan Center Tokyo, Japan;Mitsuoka T 1981:72-88.

55. Kato I, Kobayashi S, Yokokura T, Mutai M: Antitumor activity of Lactobacillus casei in mice. Gann 1981, 72:517-523.

56. Matsuzaki T, Yokokura T, Azuma I: Anti-tumour activity of Lactobacillus casei on Lewis lung carcinoma and line-10 hepatoma in syngeneic mice and guinea pigs. Cancer Immunol Immunother 1985, 20:18-22.

57. Miake S, Nomoto K, Yokokura T, Yoshikai Y, Mutai M, Nomoto K: Protective effect of Lactobacillus casei on Pseudomonas aeruginosa infection in mice. Infect Immun 1985, 48:480-485.

58. Matsuzaki T, Yokokura T, Mutai M: Antitumor effect of intrapleural administration of Lactobacillus casei in mice. Cancer Immunol Immunother 1988, 26:209-214.

59. Aso $Y$, Akaza H, Kotake T, Tsukamoto T, Imai K, Naito S: Preventive effect of a Lactobacillus casei preparation on the recurrence of superficial bladder cancer in a double-blind trial. The BLP Study Group. Eur Urol 1995, 27:104-109.

60. Aso Y, Akazan H: Prophylactic effect of a Lactobacillus casei preparation on the recurrence of superficial bladder cancer. BLP Study Group. Urol Int 1992, 49:125-129.

61. Matsuzaki T: Immunomodulation by treatment with Lactobacillus casei strain Shirota. Int J Food Microbiol 1998, 41:133-140.

62. Malaguarnera G, Leggio F, Vacante M, Motta M, Giordano M, Biondi A, Basile F, Mastrojeni S, Mistretta A, Malaguarnera M, Toscano MA, Salmeri M: Probiotics in the gastrointestinal diseases of the elderly. J Nutr Health Aging 2012, 16:402-10.

63. Takagi A, Matsuzaki T, Sato M, Nomoto K, Morotomi M, Yokokura T: Inhibitory effect of oral administration of Lactobacillus casei on 3methylcholanthrene-induced carcinogenesis in mice. Med Microbiol Immunol 1999, 188:111-116.

64. Baral RN, Maity P: Induction of colorectal cancer in rats by 20 methylcholanthrene. Cancer Lett 1992, 61:177-183.

65. Rao AR, Hussain SP: Modulation of methylcholanthrene-induced carcinogenesis in the uterine cervix of mouse by indomethacin. Cancer Lett 1988, 43:15-19.

66. Takagi A, Matsuzaki T, Sato M, Nomoto K, Morotomi M, Yokokura T: Enhancement of natural killer cytotoxicity delayed murine carcinogenesis by a probiotic microorganism. Carcinogenesis 2001 22:599-605.

67. Imai K, Matsuyama S, Miyake S, Suga K, Nakachi K: Natural cytotoxic activity of peripheral-blood lymphocytes and cancer incidence: an 11year follow-up study of a general population. Lancet 2000, 356:1795-1799.

68. Foligne B, Zoumpopoulou G, Dewulf J, Ben Younes A, Chareyre F, Sirard JC, Pot B, Grangette C: A key role of dendritic cells in probiotic functionality. PLoS One 2007, 2:313.

69. Banchereau J, Steinman RM: Dendritic cells and the control of immunity. Nature 1998, 392:245-252.

70. Yasui $\mathrm{H}$, Shida K, Matsuzaki T, Yokokura T: Immunomodulatory function of lactic acid bacteria. Antonie Van Leeuwenhoek 1999, 76:383-389.

71. Takagi A, Ikemura H, Matsuzaki T, Sato M, Nomoto K, Morotomi M, Yokokura T: Relationship between the in vitro response of dendritic cells to Lactobacillus and prevention of tumorigenesis in the mouse. J Gastroenterol 2008, 43:661-669. 
72. Matsumoto S, Hara T, Nagaoka M, Mike A, Mitsuyama K, Sako T, Yamamoto M, Kado S, Takada T: A component of polysaccharide peptidoglycan complex on Lactobacillus induced an improvement of murine model of inflammatory bowel disease and colitis-associated cancer. Immunology 2009, 128:e170-180.

73. Lee JW, Shin JG, Kim EH, Kang HE, Yim IB, Kim JY, Joo HG, Woo HJ: Immunomodulatory and antitumor effects in vivo by the cytoplasmic fraction of Lactobacillus casei and Bifidobacterium longum. J Vet Sci 2004, 5:41-48.

74. Elmore S: Apoptosis: a review of programmed cell death. Toxicol Pathol 2007, 35:495-516.

75. Fesik SW: Promoting apoptosis as a strategy for cancer drug discovery. Nat Rev Cancer 2005, 5:876-885.

76. Iyer C, Kosters A, Sethi G, Kunnumakkara AB, Aggarwal BB, Versalovic J: Probiotic Lactobacillus reuteri promotes TNF-induced apoptosis in human myeloid leukemia-derived cells by modulation of NF-kappaB and MAPK signalling. Cell Microbiol 2008, 10:1442-1452.

77. Otte JM, Mahjurian-Namari R, Brand S, Werner I, Schmidt WE, Schmitz F: Probiotics regulate the expression of COX-2 in intestinal epithelial cells. Nutr Cancer 2009, 61:103-113.

78. Sano H, Kawahito Y, Wilder RL, Hashiramoto A, Mukai S, Asai K, Kimura S, Kato $\mathrm{H}$, Kondo $\mathrm{M}$, Hla T: Expression of cyclooxygenase-1 and -2 in human colorectal cancer. Cancer Res 1995, 55:3785-3789.

79. Tsujii M, DuBois RN: Alterations in cellular adhesion and apoptosis in epithelial cells overexpressing prostaglandin endoperoxide synthase 2 . Cell 1995, 83:493-501.

80. Chan TA, Morin PJ, Vogelstein B, Kinzler KW: Mechanisms underlying nonsteroidal antiinflammatory drug-mediated apoptosis. Proc Natl Acad Sci U S A 1998, 95:681-686.

81. Le Leu RK, Brown IL, Hu Y, Bird AR, Jackson M, Esterman A, Young GP: A synbiotic combination of resistant starch and Bifidobacterium lactis facilitates apoptotic deletion of carcinogen-damaged cells in rat colon. J Nutr 2005, 135:996-1001.

82. Baricault L, Denariaz G, Houri JJ, Bouley C, Sapin C, Trugnan G: Use of HT29, a cultured human colon cancer cell line, to study the effect of fermented milks on colon cancer cell growth and differentiation. Carcinogenesis 1995, 16:245-252.

83. Grimoud J, Durand H, de Souza S, Monsan P, Ouarné F, Theodorou V, Roques $C$ : In vitro screening of probiotics and synbiotics according to anti-inflammatory and anti-proliferative effects. Int J Food Microbiol 2010 144:42-50.

84. Marvin-Guy LF, Duncan P, Wagnière S, Antille N, Porta N, Affolter M, Kussmann M: Rapid identification of differentiation markers from whole epithelial cells by matrix-assisted laser desorption/ionisation time-offlight mass spectrometry and statistical analysis. Rapid Commun Mass Spectrom 2008, 22:1099-1108.

85. Singh J, Rivenson A, Tomita M, Shimamura S, Ishibashi N, Reddy BS: Bifidobacterium longum, a lactic acid-producing intestinal bacterium inhibits colon cancer and modulates the intermediate biomarkers of colon carcinogenesis. Carcinogenesis 1997, 18:833-841.

86. Moorehead RJ, Hoper M, McKelvey ST: Assessment of ornithine decarboxylase activity in rectal mucosa as a marker for colorectal adenomas and carcinomas. Br J Surg 1987, 74:364-365.

87. Mai V: Dietary modification of the intestinal microbiota. Nutr Rev 2004 62:235-242.

88. Topping DL, Clifton PM: Short-chain fatty acids and human colonic function: roles of resistant starch and nonstarch polysaccharides. Physiol Rev 2001, 81:1031-1064.

89. Whitehead RH, Young GP, Bhathal PS: Effects of short chain fatty acids on a new human colon carcinoma cell line (LIM1215). Gut 1986, 27:1457-1563.

90. Clausen MR, Bonnén H, Mortensen PB: Colonic fermentation of dietary fibre to short chain fatty acids in patients with adenomatous polyps and colonic cancer. Gut 1991, 32:923-928.

91. Walker AR, Walker BF, Walker AJ: Faecal pH, dietary fibre intake, and proneness to colon cancer in four South African populations. $\mathrm{Br} J$ Cancer 1986, 53:489-495

92. Ohkawara S, Furuya H, Nagashima K, Asanuma N, Hino T: Oral administration of butyrivibrio fibrisolvens, a butyrate-producing bacterium, decreases the formation of aberrant crypt foci in the colon and rectum of mice. J Nutr 2005, 135:2878-2883.
93. Lan A, Lagadic-Gossmann D, Lemaire C, Brenner C, Jan G: Acidic extracellular $\mathrm{pH}$ shifts colorectal cancer cell death from apoptosis to necrosis upon exposure to propionate and acetate, major end-products of the human probiotic propionibacteria. Apoptosis 2007, 12:573-591.

94. Jan G, Belzaca AS, Haouzi D, Rouault A, Métivier D, Kroemer G, Brenner C: Propionibacteria induce apoptosis of colorectal carcinoma cells via short-chain fatty acids acting on mitochondria. Cell Death Differ 2002, 9:179-188

95. Borowicki A, Michelmann A, Stein K, Scharlau D, Scheu K, Obst U, Glei M: Fermented wheat aleurone enriched with probiotic strains LGG and Bb12 modulates markers of tumor progression in human colon cells. Nutr Cancer 2011, 63:151-160.

96. Evans NP, Misyak SA, Schmelz EM, Guri AJ, Hontecillas R, Bassaganya-Riera J: Conjugated linoleic acid ameliorates inflammation-induced colorectal cancer in mice through activation of PPARgamma. J Nutr 2010, 140:515-521.

97. Kelley NS, Hubbard NE, Erickson KL: Conjugated linoleic acid isomers and cancer. J Nutr 2007, 137:2599-2607.

98. Kim KH, Park HS: Dietary supplementation of conjugated linoleic acid reduces colon tumor incidence in $\mathrm{DMH}$-treated rats by increasing apoptosis with modulation of biomarkers. Nutrition 2003, 19:772-777.

99. Liew C, Schut HA, Chin SF, Pariza MW, Dashwood RH: Protection of conjugated linoleic acids against 2-amino-3- methylimidazo[4,5-f] quinoline-induced colon carcinogenesis in the F344 rat: a study of inhibitory mechanisms. Carcinogenesis 1995, 16:3037-3043.

100. Ewaschuk JB, Walker JW, Diaz H, Madsen KL: Bioproduction of conjugated linoleic acid by probiotic bacteria occurs in vitro and in vivo in mice. $J$ Nutr 2006, 136:1483-1487.

101. Lemmon MA, Schlessinger J: Cell signaling by receptor tyrosine kinases. Cell 2010, 141:1117-1134

102. Sullivan A, Nord CE: The place of probiotics in human intestinal infections. Int J Antimicrob Agents 2002, 20:313-319.

103. Guslandi M, Mezzi G, Sorghi M, Testoni PA: Saccharomyces boulardii in maintenance treatment of Crohn's disease. Dig Dis Sci 2000, 45:1462-1464.

104. Czerucka D, Dahan S, Mograbi B, Rossi B, Rampal P: Saccharomyces boulardii preserves the barrier function and modulates the signal transduction pathway induced in enteropathogenic Escherichia coliinfected T84 cells. Infect Immun 2000, 68:5998-6004.

105. Czerucka D, Roux I, Rampal P: Saccharomyces boulardii inhibits secretagogue-mediated adenosine 3',5'-cyclic monophosphate induction in intestinal cells. Gastroenterology 1994, 106:65-72.

106. Hynes NE, MacDonald G: ErbB receptors and signaling pathways in cancer. Curr Opin Cell Biol 2009, 21:177-184.

107. Chen X, Fruehauf J, Goldsmith JD, Xu H, Katchar KK, Koon HW, Zhao D, Kokkotou EG, Pothoulakis C, Kelly CP: Saccharomyces boulardii inhibits EGF receptor signaling and intestinal tumor growth in $\mathrm{Apc}(\mathrm{min})$ mice. Gastroenterology 2009, 137:914-923.

108. Moser AR, Luongo C, Gould KA, McNeley MK, Shoemaker AR, Dove WF: ApcMin: a mouse model for intestinal and mammary tumorigenesis. Eur J Cancer 1995, 31A:1061-1064.

109. Ma EL, Choi YJ, Choi J, Pothoulakis C, Rhee SH, Im E: The anticancer effect of probiotic Bacillus polyfermenticus on human colon cancer cells is mediated through ErbB2 and ErbB3 inhibition. Int J Cancer 2010, 127:780-790.

110. Gill Cl, Rowland IR: Diet and cancer: assessing the risk. Br J Nutr 2002, 88:73-87.

111. Rafter J, Govers M, Martel P, Pannemans D, Pool-Zobel B, Rechkemmer G, Rowland I, Tuijtelaars S, van Loo J: PASSCLAIM-diet-related cancer. Eur J Nutr 2004 , 43:147--1184

doi:10.1186/1471-2482-12-S1-S35

Cite this article as: Uccello et al:: Potential role of probiotics on colorectal cancer prevention. BMC Surgery 2012 12(Suppl 1):S35. 